\title{
The Analysis on the Water-Sediment Characteristics and the Influences of Sluice Construction in Jiaojiang River Estuary
}

\author{
Xia Weiyi $^{1, *}$, Zhao Xiaodong ${ }^{1}$, Zhang Xinzhou $^{1}$ and Yang Kangkai ${ }^{2}$ \\ ${ }^{1}$ Nanjing Hydraulic Reasearch Institute, Nanjing, Jiangsu, 210029, P.R. China \\ ${ }^{2}$ Ministry of Environmental Protection of Gaochun District, Nanjing, Jiangsu, 211300, P.R. China
}

\begin{abstract}
According to the field observation data of Jiaojiang River estuary in the dry season of 2013 and the flood season of 2014, the paper has analyzed the variation of water-sediment characteristics among three river sections (Lingjiang River, Jiaojiang River and Jiaojiang River Mouth). Based on the underwater topographic data in recent years, the erosion and deposition evolution of riverbed has been studied. The effect of the relative strength of runoff and tide on the water-sediment characteristics and the riverbed evolution has been discussed according to data analysis. The effect made by sluice construction in the river and estuary has also been discussed employing the result of numerical simulation research made by Nanjing Hydraulic Research Institute.
\end{abstract}

Keywords: Jiaojiang River estuary, water flow, sediment, tidal sluice.

\section{INTRODUCITON}

Jiaojiang River system is the third largest in Zhejiang Province, originated from Tiantangjian between Xianju County and Jinyun County. The main stream flows through Yongan Brook, Lingjiang River and Jiaojiang River into the the Taizhou Bay in the east. The total length is about $209 \mathrm{~km}$ and the basin area is about $6603 \mathrm{~km}^{2}$ (see Fig. 1).

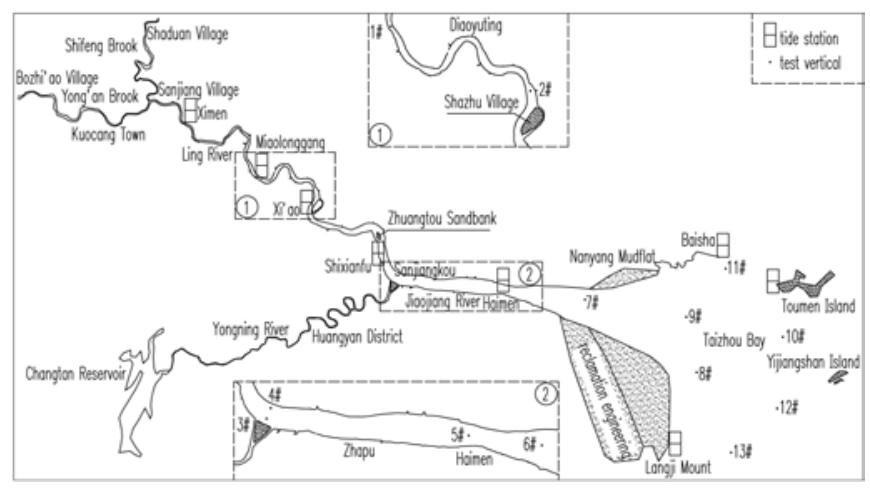

Fig. (1). Diagrammatic sketch of Jiaojiang River system.

Jiaojiang River estuary possesses the characteristics of mountain streams and strong tide. The tidal current limit can extend to the Sanjiang Village which is the starting point of Lingjiang River. Jiaojiang River estuary consists of Lingjiang River, Jiaojiang River and Jiaojiang River Mouth after the completion of the brake in Yongning River. Yong'an Brook and Shifeng Brook, upstream of Lingjiang River, is about $132 \mathrm{~km}$ and $134 \mathrm{~km}$ long respectively. The midstream of Lingjiang River, from Sanjiang Village to Miaolonggang, is about $17.5 \mathrm{~km}$ long and $170-380 \mathrm{~m}$ wide.

*Address correspondence to this author Nanjing Hydraulic Reasearch Institute, Nanjing, Jiangsu, 210029, P.R. China; Tel: +86 13813066839; E-mail: 335056446@qq.com
Jiaojiang River, from Sanjiangkou to Niutoujing, is about 12 $\mathrm{km}$ long and 880-1800 m wide. Jiaojiang River Mouth is the river reach of broadening formation widening from Niutoujing to Taizhou Bay.

The human activities in Jiaojiang River estuary are relatively frequent in recent years. The estuarine hydrodynamic characteristics and boundary conditions are significantly changed by waterway regulation, reservoir and sluice construction, sand excavation, etc. The decrease of the runoff and flood peak flow, cooperating with the mutual jacking effect of flood and tide, has resulted in watercourse siltation and river water becoming muddy. It has also made adverse effect on the water resources utilization, flood control and drainage, ports and shipping, etc. To solve these problems, the units concerned are planning the sluice construction project in Jiaojiang River estuary. The locations of sluices are temporarily schemed to be Miaolonggang and Jiaojiang River Mouth. Based on past experience, sluice constructions in the sandy estuaries will cause the silting problems. The fundamental reason is that sluice constructions will change the nature conditions and the ecological environment in estuaries. Sluice constructions in Jiaojiang River estuary which has complicated watersediment conditions must be sufficiently and scientifically considered. This paper will analyze the water and sediment characteristics in Jiaojiang River estuary in recent years, so as to provide technical support for selection of sluice sites and reference for research of silting problems.

\section{DATA SOURCES AND RESEARCH METHODS}

This paper is based on the large-scale hydrologic and sediment survey data gathered by thirteen test verticals and eight tide stations (the positions see Fig. 1) of Jiaojiang River estuary in December ,2013 (dry season) and June, 2014 (flood season). The observation content mainly 
Table 1. The flux and tidal type in the hydrologic survey period.

\begin{tabular}{|c|c|c|c|}
\hline \multirow{3}{*}{ Season } & survey period & Type of tide & Average daily flux (m $\left.\mathbf{m}^{3} / \mathbf{s}\right)$ \\
\hline \hline \multirow{3}{*}{ dry season } & $2013.12 .4-12.5$ & Spring tide & $4.17-4.86$ \\
\cline { 2 - 5 } & $2013.12 .8-12.9$ & moderate tide & $5.02-4.88$ \\
\cline { 2 - 5 } & $2013.12 .12-12.13$ & neap tide & $6.22-6.30$ \\
\hline \multirow{3}{*}{ flood season } & $2014.6 .14-6.15$ & Spring tide & $20-20.5$ \\
\cline { 2 - 5 } & $2014.6 .18-6.19$ & moderate tide & $21.8-23.3$ \\
\cline { 2 - 5 } & $2014.6 .21-6.22$ & neap tide & $46.9-387$ \\
\cline { 2 - 5 } & $2014.6 .22-6.23$ & Neap tide (flood) & $387-1200$ \\
\hline
\end{tabular}

includes water level observation, hydrologic and sediment tests in fixed sites, underway measurement, water quality test, bottom sediment sampling test, cross-sectional flow observation, etc. [1]. The flux of Baizhi'ao Station and tidal type of the hydrologic survey period are shown in Table $\mathbf{1}$. The hydrological elements and sediment characteristics (e.g. runoff, tide, tidal current, sediment concentration) are preliminarily analyzed; the erosion and deposition evolution of riverbed is studied according to comparing underwater topographic data in recent years. The purpose of this paper is to provide technical support for mathematical model calculation, engineering design, etc.

\section{THE WATER-SEDIMENT CHARACTERISTICS IN JIAOJIANG RIVER ESTUARY}

\subsection{Runoff}

The annual distribution of Jiaojiang River basin is asymmetrical obviously: the annual average runoff from May to September accounts for $60-70 \%$ of annual runoff, especially the runoff in one month can reach $40-50 \%$ of the annual runoff. The annual runoff $\left(\mathrm{m}^{3} / \mathrm{s}\right)$ in respective sections of Jiaojiang River basin is shown in Table 2.

\subsection{Tide}

Jiaojiang River estuary possesses the characteristics of irregular semidiurnal tide. The tidal current limit can extend to the Sanjiang Village which is the starting point of Lingjiang River. The tidal limit is near Wangyangdian Village which is $3 \mathrm{~km}$ upstream of the tidal current limit [2].
The tidal waves propagate from the estuary of broadening formation to Jiaojiang River, flow upstream into Lingjiang River through Sanjiangkou. The tidal wave deforms similarly to the standing wave under the mutual jacking effect of flood and tide. As a result, the time difference between ebb tide and floodtide increases gradually up to 4h40min. According to historical data [3], the tidal range increased within a certain distance from Haimen to upper stream, then decreased. However, according to recent data, the tidal range increased gradually from Taizhou Bay to upper stream (see Fig. 2). The high water level rised up to $4.68 \mathrm{~m}$ gradually and the largest tidal range reached $6.85 \mathrm{~m}$ near Ximen. The change of tidal characteristics is mainly due to human activities in recent years. A large-scale sand excavation was implemented in Jiaojiang River and Lingjiang River in 1983-2004. It made the riverbed surface elevation of Lingjiang River decline averagely by about $2 \mathrm{~m}$ [3]. The terrain friction effect on the upstream tidal wave decreased along with the riverway deepening, the bottom slope becoming gentle and the diara disappearing. The tidal energy propagated upstream easily. The high water level rised up but the low water level reduced. As a result, the tidal range increased by about $1.5 \mathrm{~m}$ near Linhai station.

It is worth noting that the smallest tidal range reduced abnormally to $1.25 \mathrm{~m}$ near Ximen in June, 2014. Two abnormal fluctuations occurred on the tidal process line (see Fig. 3). We found that the two fluctuations appeared both in the flood peaks. It demonstrated that the flood enhanced the riverway flux but weakened the tidal wave effect. The low tide level rised up significantly and the high tide level manifested no abnormity. As a result, the tidal range

Table 2. The annual runoff $\left(\mathrm{m}^{3} / \mathrm{s}\right)$ in respective sections in Jiaojiang River basin.

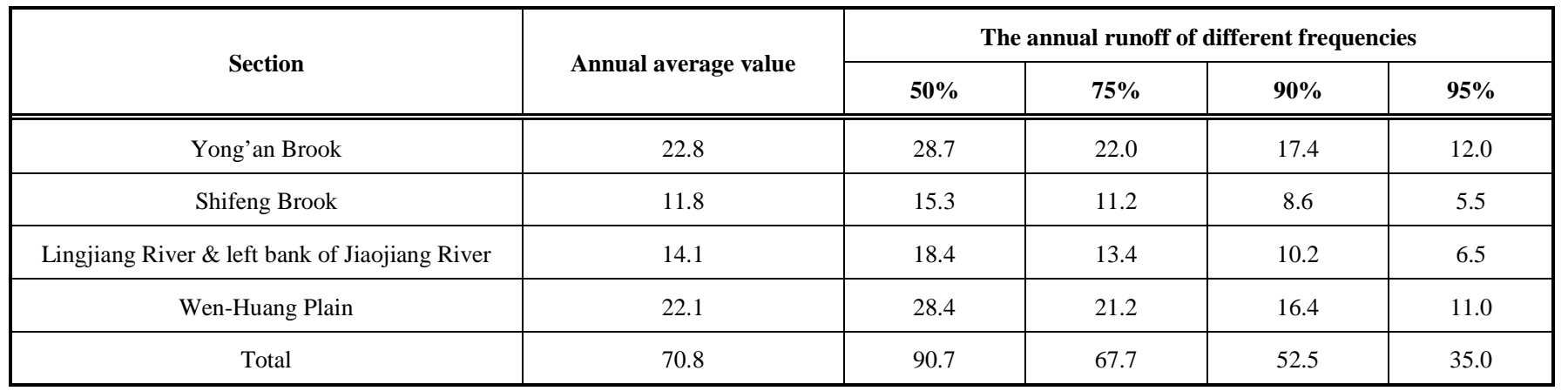


decreased significantly. The riverway was controlled by the flood at the moment.

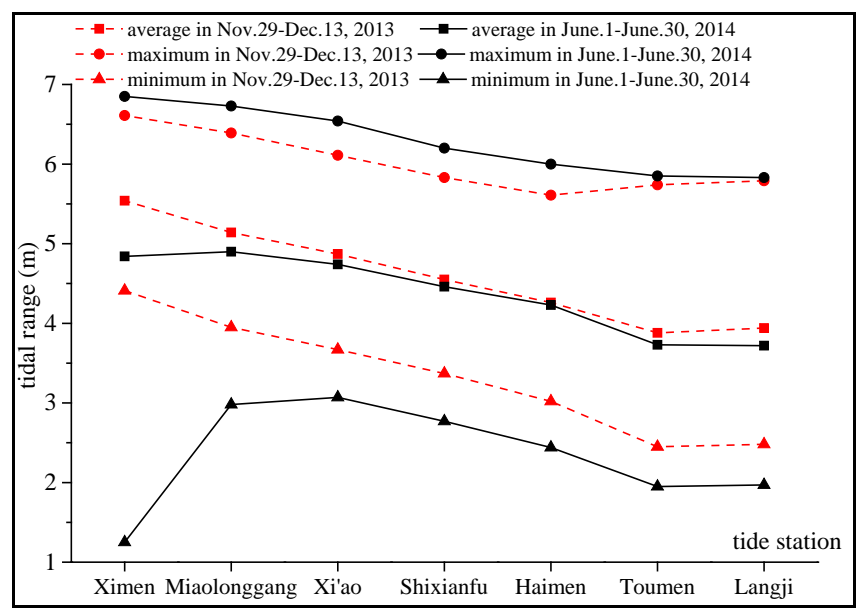

Fig. (2). The changes of tidal range along the river.

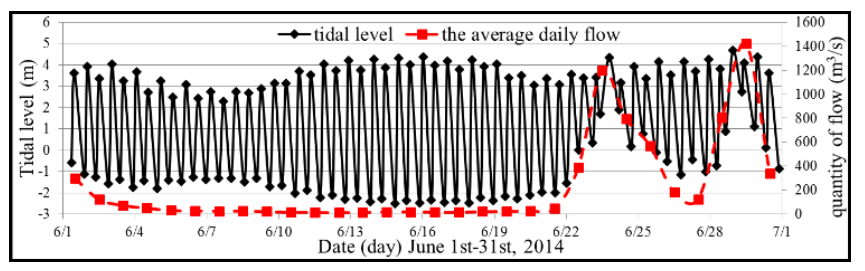

Fig. (3). The tidal process line.

\subsection{Tidal Current}

The rectilinear current is the main mode of motion in Lingjiang River and Jiaojiang River. Approximately the tidal inlet (8\#-9\# test verticals) also manifests the characteristics of rectilinear current under the constraint of Taizhou Islands and Dongji Islands. The tidal current in the open waters (10\#-13\# test verticals) without the shield of islands manifests obvious motion of rotation. Generally the north is more obvious than the south on the rotation in Taizhou Bay.

According to Fig. (4), the vertical average flow velocity distribution during the spring tide of mean velocity distribution presented increasing trend from Taizhou Bay to Lingjiang River generally. The flow velocity of flood tide was greater than that of ebb tide in Jiaojiang River and Lingjiang River. But there was little difference in the flow velocity between the flood tide and the ebb tide in Taizhou Bay.

The maximum vertical average flow velocity of flood tide was about $0.57-1.70 \mathrm{~m} / \mathrm{s}$ in Taizhou Bay, 1.57-2.30 m/s in Jiaojiang River, and 1.42-2.28 m/s near Miaolonggang and Xi'ao in Lingjiang River. The idem value of ebb tide was $0.51-1.45 \mathrm{~m} / \mathrm{s}$ in Taizhou Bay, $1.01-2.00 \mathrm{~m} / \mathrm{s}$ in Jiaojiang River, and 1.48-1.90 m/s near Miaolonggang and Xi'ao in Lingjiang River.

It is worth noting that the flow velocity of flood tide was less in Sanjiangkou (3\# and 4\# test vertical line) than the adjacent river reaches, but the ebb tide behaved in the opposite way. Similarly, the flow velocity of flood tide was greater in the vicinity of Haimen (5\# test vertical line) than the adjacent river reaches, but the ebb tide behaved in the opposite way.

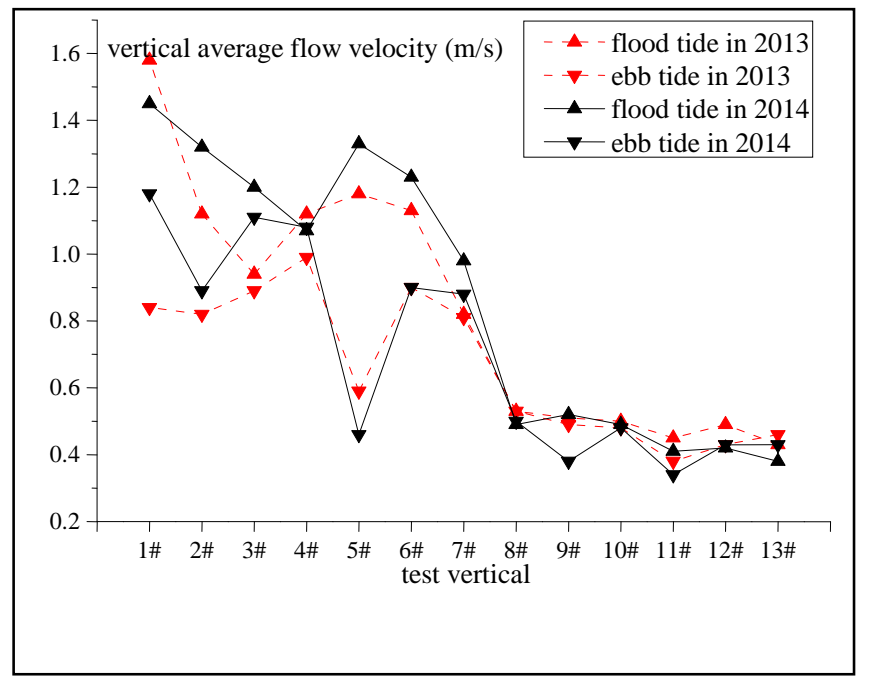

Fig. (4). The vertical average flow velocity of flood and ebb tide in December 4th-5th, 2013 and June 14th-15th, 2014.

\subsection{Sediment}

The sediment of Jiaojiang River originates from the land field and sea field. The sediment sources of Jiaojiang River estuary include the sediment carried by runoff or flood from the land field is mainly concentrated in the flood season. The coarse particulate matter mainly deposits inside the river entrance and hardly moves outside; the fine particulate matter moves back and forth along with the tidal current and participates in shaping the estuary with the fine particulate matter from the sea. However, the sea field is the main source of estuary sediment.

\subsubsection{The Spatial Distribution of Sediment Concentration}

In the lengthways direction, the sediment concentration is low in both sides but high in the middle in Jiaojiang River estuary. It reflects the turbidity maximum existing. The vertical average sediment concentration of spring tide was about $14 \mathrm{~kg} / \mathrm{m}^{3}$ near Miaolonggang in the dry season of 2013; it increased to $19 \mathrm{~kg} / \mathrm{m}^{3}$ near Xi'ao downstream. Afterwards, the concentration began to decrease gradually and became about $5 \mathrm{~kg} / \mathrm{m}^{3}$ near Haimen.

In the widthways direction, the vertical average sediment concentration of left bank was less than that of right bank in the dry season according to the data of $3 \#$ (right bank) and 4\# (left bank) test verticals. But the situation of flood season was contrary. The runoff intensity is greater than the tidal current intensity in the flood season. The main current controlled by the runoff deviates to the right bank under the effort of the Coriolis force. Therefore, a circumfluence of flow forms in the widthways direction. It scours and carries the sediment from the right bank to the left bank, so as to form the zone of higher sediment concentration. However, the main current is controlled by tidal current in the dry season. The current flowing upstream deviates to the left bank. The circumfluence direction of dry season is contrary to that of flood season. As a result, the right bank is higher in the sediment concentration. 
In the vertical direction, the sediment concentration gets increasingly higher from the top to bottom layer. The sediment concentration gradient increases along with the transformation of spring tide, moderate tide and neap tide. The phenomenon of incremental sediment concentration in the phenomenon comes second in Jiaojiang River and becomes hardly obvious in Taizhou Bay. The fluid mud and shoal emerge on the riverbed. The sediment of riverbed surface resuspends under the entrainment influence of current. As a result, the sediment concentration increases obviously. The sediment enters into the riverway with tidal current or moves downstream with runoff. It is why the sediment concentration in the bottom is high both in the flood and dry season.

\subsubsection{The Time Distribution of Sediment Concentration}

The flood season is lower than the dry season in the sediment concentration in Jiaojiang River estuary. But some particular cases occurred; the dry season of 2013 was almost lower than the flood season of 2014 in the vertical average sediment concentration of $3 \#-6 \#$ test verticals during the period of spring tide. It is because the turbidity maximum was near Shixianfu in the flood season of 2014 but near Xi'ao in the dry season of 2013; both the sediment concentration distribution curves intersect at $3 \#$ test vertical (see Fig. 5). The sediment concentration is closely related to the dynamic change of runoff and tidal current. The sediment transport in mass occurs as the transformation of dry and flood season happens. The sediment concentration distribution will change with the runoff intensity. The turbidity maximum will move downstream and even outside the river entrance along with the runoff intensity enhancing.

The sediment concentration also changes with the tidal intensity. Generally, the concentration increases quickly along with the augment of tidal current velocity. The dynamic intensity of spring tide and moderate tide is strong so that the sediment concentration is high relatively. The dynamic intensity of neap tide is weaker so that the sediment concentration gets lower. For example, the vertical average sediment concentration of spring tide, moderate tide and neap tide of 2013 was respectively $10.6-19.0 \mathrm{~kg} / \mathrm{m}^{3}$, 8.7-17.6 $\mathrm{kg} / \mathrm{m}^{3}, 8.1-10.1 \mathrm{~kg} / \mathrm{m}^{3}$ in Lingjiang River and 5.1-10.4 $\mathrm{kg} / \mathrm{m}^{3}, 3.91-10.75 \mathrm{~kg} / \mathrm{m}^{3}, 1.6-9.1 \mathrm{~kg} / \mathrm{m}^{3}$ in Jiaojiang River.

\subsubsection{Sediment Transport Rate and Sediment Discharge Per Unit Width}

The sediment transport rate gradually decreases with the tidal intensity weakening; it is higher in the flood tide than in the ebb tide in Jiaojiang River estuary. The evolution of erosion and deposition of the riverbed in the short-term is the result of non-equilibrium sediment transport of flood and ebb tide. The tidal sediment transport is different for diverse tidal ranges or tidal intensity. According to the data of inflow sediment discharge in $5 \#$ test vertical of Haimen, the net inflow sediment discharge is the most in the moderate tide, the second most in the spring tide and the least in the neap tide. The deformation of tidal wave gets severer with the stronger tidal intensity and larger tidal range. It makes the velocity ratio of flood and ebb tidal current higher. As a result, the net inflow sediment discharge of the whole tide increases. If the tidal range is especially large, the net input sediment discharge of flood tide will increase not much, but the sediment output will augment with the sediment carrying capacity of ebb tide enhancing. As a result, the net input sediment discharge of Haimen section decreases instead.

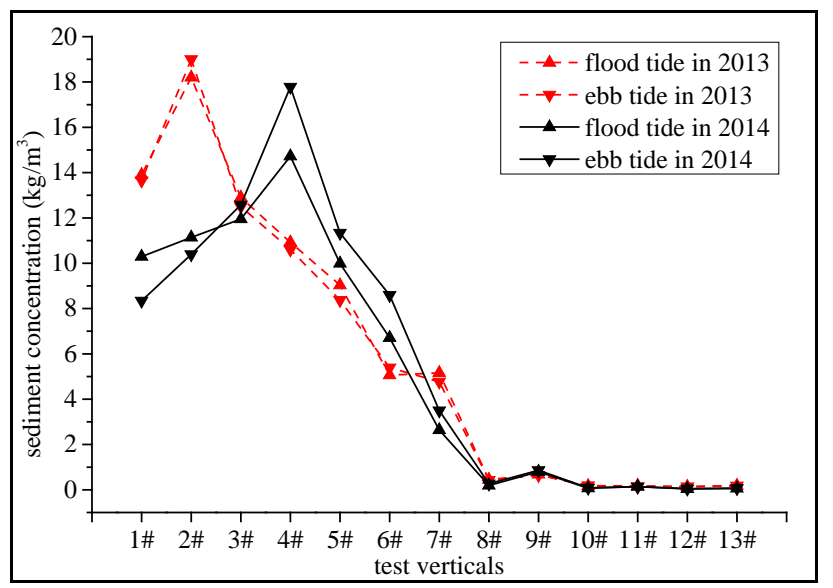

Fig. (5). The vertical average sediment concentration of flood and ebb tide in December 4th-5th, 2013 and June 14th-15th, 2014.

\subsubsection{The Particle Size of Suspended and Bottom Sediment}

The median particle size of suspended sediment in each test vertical is $0.005-0.0102 \mathrm{~mm}$, and that of bottom sediment is $0.0033-0.0321 \mathrm{~mm}$ (see Fig. 6).

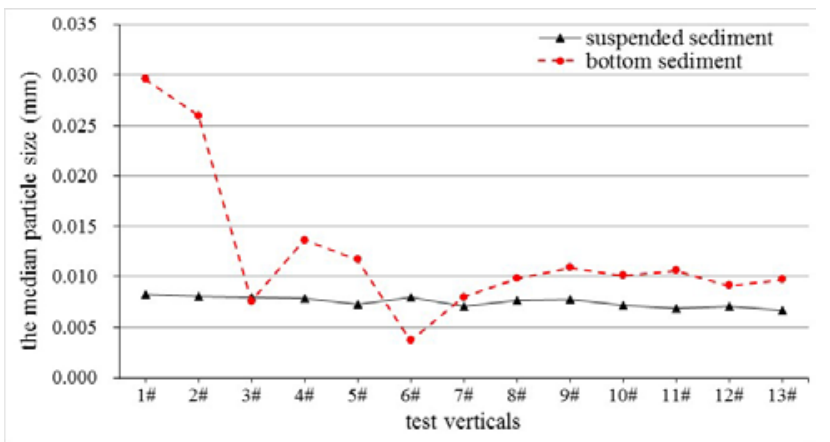

Fig. (6). The average median particle size in each vertical.

The particle size is significantly larger in Lingjiang River than in Jiaojiang River and Taizhou Bay. Jiaojiang River and Taizhou Bay differ hardly in the particle size of suspended and bottom sediment which exchange frequently.

\section{THE RIVERBED EVOLUTION OF EROSION AND DEPOSITION IN RECENT YEARS}

The riverbed evolution of Jiaojiang River estuary is influenced not only by natural factors, but also by human activities (e.g. waterway regulation, construction of reservoir and sluice, sand excavation). Based on the underwater topographic data of Jiaojiang River estuary in recent years, the author has plotted the variation diagram of erosion and deposition of riverbed and the variation diagram of talwegs in Jiaojiang River. The evolution of erosion and deposition in each river reach is briefly described in the following. 


\subsection{The Riverbed Evolution of Erosion and Deposition in Lingjiang River}

According to the research [4], the riverbed of Lingjiang River gave priority to erosion in 1970-2005. Especially the wide scope of sand excavation has accelerated the erosion after 1990s. However, the relevant departments have strengthened the sand excavation management and established the areas which is off limits for excavation after 2004. As a result, the erosion trend has been mitigated and a certain degree of back-silting has emerged.

Both the erosion and deposition had occurred on the riverbed of Lingjiang River from 2005 to 2013 (see Figs 79). The siltation in most areas was $0.5-1 \mathrm{~m}$ thickness; the siltation of concave bank was serious. The areas of erosion were mainly located in the convex bank and narrow riverway; the erosion was mainly $0-1 \mathrm{~m}$ depth and reached more than $1 \mathrm{~m}$ depth in the local area.

Figs. (7-8) shows that the upstream reach of Miaolonggang forced on the erosion and the downstream reach took the deposition as the primary. The reason of upstream erosion may be that the tidal wave had weakened near Miaolonggang; the flow velocity ratio between flood and ebb tide had decreased with the runoff strengthening; the more erosion made by runoff discharging downstream than the deposition made by tidal carrying had resulted in the gradual transformation from deposition to erosion. According to the data of the dry season of 2013, Miaolonggang section gave priority to the net export sediment discharge. The author infers that the section will still take the net export sediment discharge as the primary after the runoff strengthening in the flood season. The characteristics of "upstream erosion and downstream deposition" have resulted in Miaolonggang section being the equilibrium position of erosion and deposition in Lingjiang River in recent years. Figs (7-8) show that Miaolonggang section was relatively stable in 2005-2013. All of the above can be the feasible conditions of sluice construction in Miaolonggang.

In terms of sediment scouring and siltation volumes in 2005-2013, the scouring volume was about $48 \times 10^{4} \mathrm{~m}^{3}$ in the reach from Wangjiangmen Bridge to Miaolonggang; the siltation volume was about $97 \times 10^{4} \mathrm{~m}^{3}$ from Miaolonggang to Guan'ao; the siltation volume was about $302 \times 10^{4} \mathrm{~m}^{3}$ from Guan'ao to Sanjiangkou. Overall, the gentle siltation has appeared in most river reaches except serious scouring appearing near Sanjiangkou in recent years. It is mainly caused by the reduced runoff in recent years and the backsilting made by limiting sand excavation.

\subsection{The Riverbed Evolution of Erosion and Deposition in Jiaojiang River}

The Jiaojiang River appears to be the shape of "lotus root" restrained by mountains on both sides. The width of riverway joint such as Niutoujing section is narrow significantly. A deep pool which is deeper than upstream and downstream river forms here. The talwegs of Jiaojiang River obviously wiggled widthways in history, but tended to be nearby Haimen Harbor in the south passage after the dike project implemented (see Fig. 10). The Jiaojiang River reach took scouring as the primary under the adjustment of riverbed caused by the dike project and the effect of high flow years. The deep grooves were scoured seriously in the south of the dike and near Niutoujing.

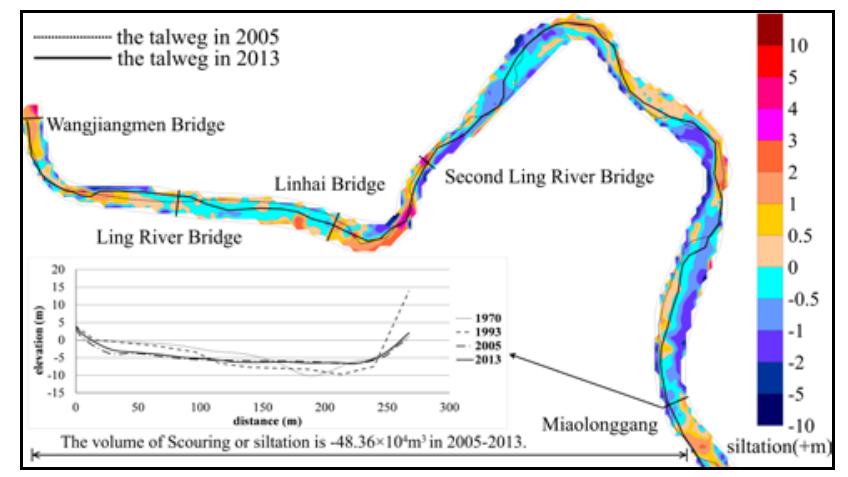

Fig. (7). The variation of erosion and deposition in the reach from Wangjiangmen Bridge to Miaolonggang.

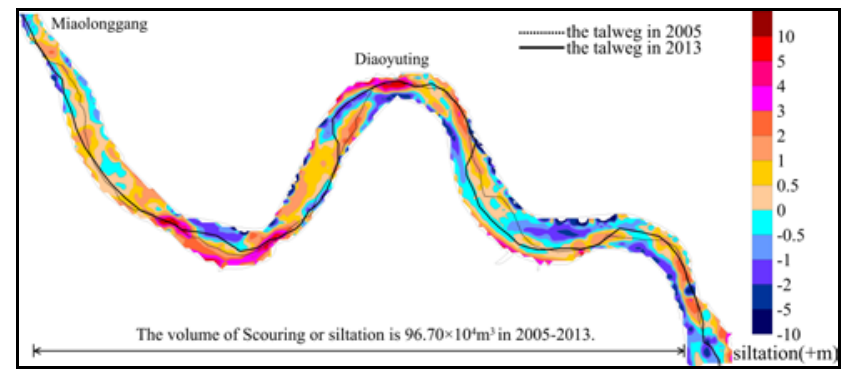

Fig. (8). The variation of erosion and deposition in the reach from Miaolonggang to Guan'ao.

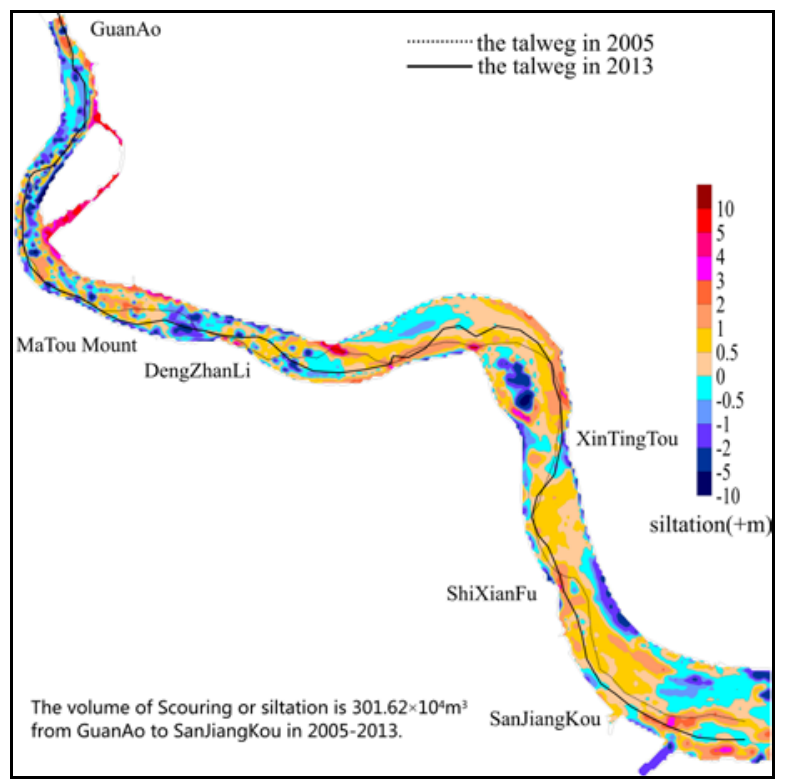

Fig. (9). The variation of erosion and deposition in the reach from Guan'ao to Sanjiangkou.

In terms of sediment scouring and siltation volumes (see Figs 11-12), the scouring volume was more than $1400 \times 10^{4}$ $\mathrm{m}^{3}$ in the reach from Huangjiao to Second Jiaojiang Bridge in 1989-2003; the siltation volume was about $200 \times 10^{4} \mathrm{~m}^{3}$ from Zhapu to Niutoujing in 2003-2013. The river channel has manifested a little scouring while shoals on both sides 
has presented slight siltation under the influence of bridge construction and reclamation project near Second Jiaojiang Bridge. The changes of erosion and deposition in Jiaojiang River in nearly 70 years have been analyzed by Li et al. [5].

The research has indicated that the influence of human activities on the adjustment of erosion and deposition was more serious than that of natural conditions in Jiaojiang River.

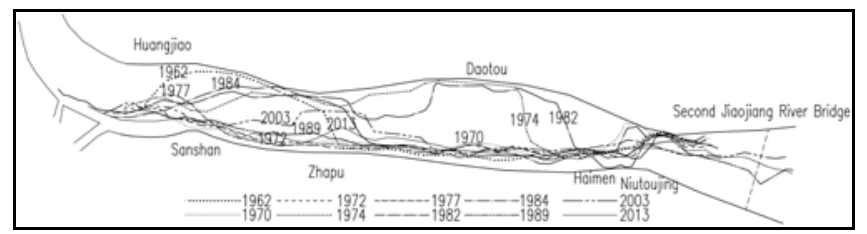

Fig. (10). The talwegs variation in history.

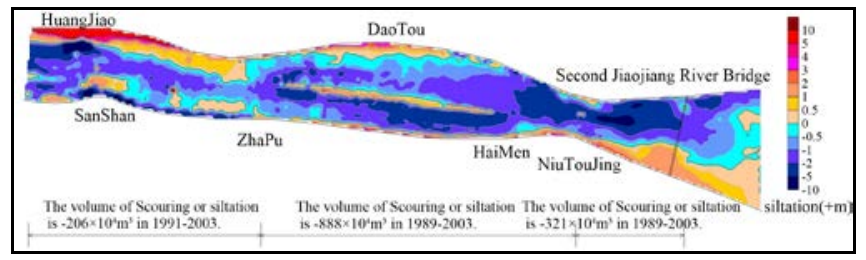

Fig. (11). the variation of erosion and deposition in 1989-2003.

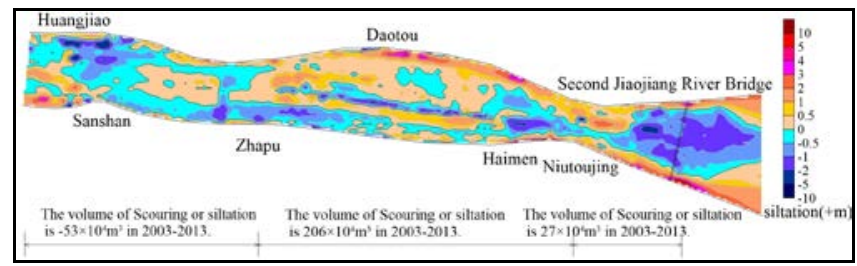

Fig. (12). the variation of erosion and deposition in 2003-2013.

\subsection{The Riverbed Evolution of Erosion and Deposition in Jiaojiang River Mouth}

The changes of landscape and water depth have been completely controlled by the engineering (e.g. shore reclamation, channel dredging) since 1990 in Jiaojiang River Mouth. The channel depth was obvious larger in 2013 than in 1989. Fig. (13) indicates that the north shoal was generally scoured by the enhanced tidal current after the reclamation and the south shoal was scoured or silted; the depth increased by $1-2 \mathrm{~m}$ along the channel.

The mouth bar area outside Jiaojiang River Mouth generally presents the characteristics of "siltation in the flood season and scouring in the dry season". The flood peak scours the riverbed and carries plenty of sediment out of the river entrance. The sediment will deposit in the mouth bar area. According to the research [6], the suspended sediment gathering and depositing near the frontal surface (the surface where the net flow velocity of the whole tide is zero) is one of the reasons why the mouth bar develops off the entrance. In the dry season, the tidal current scours the mouth bar and carries the sediment into the river entrance gradually.

\subsection{Interim Summary}

The balance of scouring and silting in Jiaojiang River estuary within the year is caused by the mutual counteraction between the scouring made by runoff and the siltation caused by tidal current. The relative balance established by the longterm interaction between the current and riverbed will accordingly adjust to the changes of current condition. The variation of tide possesses obvious cyclicity. If the annual variation of tide can be ignored, the annual variation of water and sediment conditions from upstream often decides the general trend of the evolution of estuary for years.

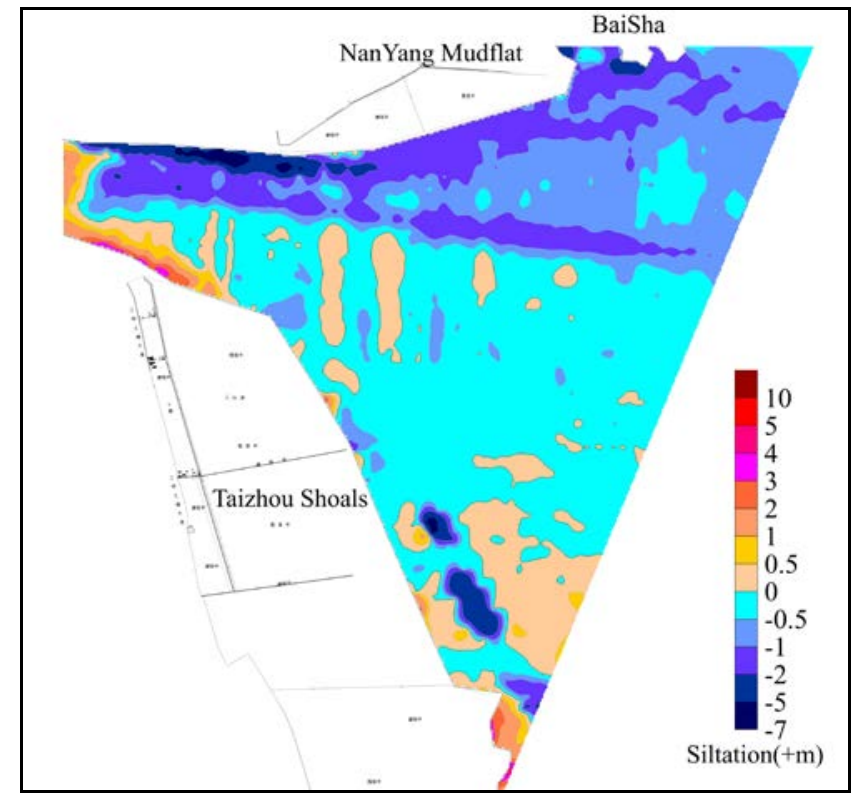

Fig. (13). the variation of erosion and deposition in Jiaojiang River Mouth from 1989 to 2013.

\section{DISCUSSION}

\subsection{The Influence Made by the Relative Strength between the Runoff and Tide on the Changes of Water- Sediment Characteristics}

Jiaojiang River estuary is the macro-tidal estuary in which the sea area is the main source of sediment. The runoff and tidal current play an important role in maintaining the natural variation of the estuary. The changes of water and sediment characteristics along the river are largely restricted by the relative strength between the runoff and tide. The water-sediment characteristics in the dry and flood season have been primarily expounded above. The high tide level appears to be higher; the tidal range and the time difference between ebb tide and flood tide present a reduction when the runoff intensity is higher in the flood season than in the dry season (see Figs 14, 15). The peak area of vertical average sediment concentration moves to the downstream 4\# test vertical from 2\# test vertical (see Fig. 5). Thus it can be seen that the changes of relative strength between the runoff and tidal current can regularly influence the characteristics of water and sediment. The turbidity maximum will move downstream along with the runoff intensity strengthening.

If the runoff and tide are compared to two forces, the fighting battlefront is the area where the water-sediment movement is active and the mixing of salt and fresh water is adequate in Jiaojiang River estuary. The "battlefront" called turbidity maximum usually will be suppressed to be nearby Xi'ao of Lingjiang River by the tide when the runoff is weak 
in the dry season; the "battlefront" will transfer to be in the downstream area of Shixianfu or Jiaojiang River; the "battlefront" will be even pushed out of the river entrance by the runoff when the flood surges. The reaches occupied by the two forces separately present their respective characteristics of water and sediment. The upstream and midstream of Lingjiang River are mainly controlled by the runoff. It results in that the water-sediment characteristics in this reach is mainly affected by the runoff. The weakened runoff will cause the sediment from sea area silting on the riverbed; the river will be silted up to die finally. Jiaojiang River and Jiaojiang River Mouth give priority to the tide. The water-sediment characteristics in this area are influenced by both the tidal wave and tidal flow. The higher tidal flow will maintain the larger section dimension of riverbed. The tide has played an important role in shaping the riverbed section. Therefore, the change of relative strength between the runoff and tide is an important factor of the evolution of erosion and deposition.

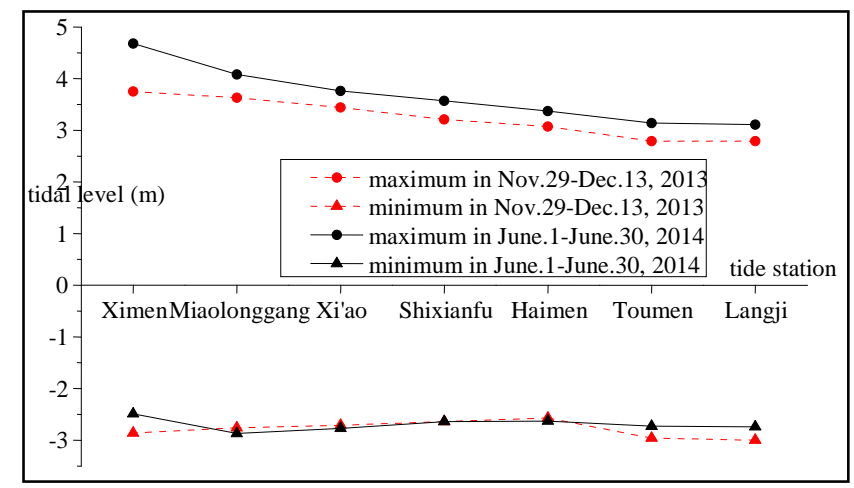

Fig. (14). The changes of tidal level along the river

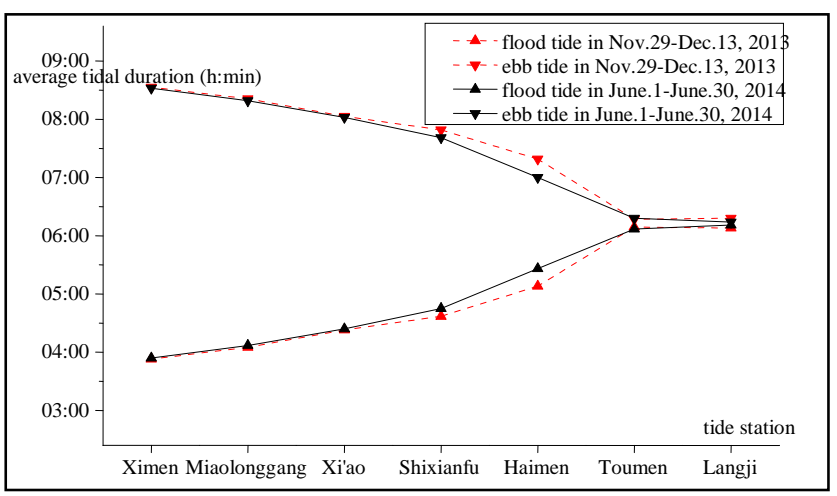

Fig. (15). The changes of flood and ebb tide duration along the river.

\subsection{The Influence Made by the Relative Strength between the Runoff and Tide on the Riverbed Evolution of Erosion and Deposition}

The riverbed evolution of erosion and deposition in Jiaojiang River estuary shows the obvious characteristics of seasonal variation. The riverbed inside Jiaojiang River entrance presents the characteristics of "scouring in the flood season and siltation in the dry season", while the riverbed outside the river entrance presents the characteristics of "siltation in the flood season and scouring in the dry season" [7]. It owns the inseparable relationship with the relative strength between the runoff and tide. Because of the runoff blocking the flood tide, accelerating the ebb tide and diluting the sediment concentration, the relative strength between the runoff and tide will change the sediment discharge ratio of flood tide to ebb tide directly, so as to affect the erosion and deposition of riverbed.

The runoff intensity will strengthen in the flood season; the riverbed will be scoured seriously when the occasional flood surges downstream. Plenty of bottom sediment will be suspended by the flood; A large number of sediment will be carried outside the river entrance and gather in the area of mouth bar, but little of it will deposit in Lingjiang River and Jiaojiang River. The turbidity maximum will also move downstream. As a result, the riverbed will be scoured inside the river entrance, while silted outside the river entrance on the whole.

The runoff intensity will weaken in the dry season; the riverbed will silt gradually when the tide is controlling Lingjiang River for most of the period. The tidal wave will deform after propagation into the riverway. The duration of flood tide will reduce, while that of ebb tide will increase; the flow velocity of flood tide will be higher than that of ebb tide; the sediment from sea area will be easily transported upstream; the turbidity maximum will move upstream. As a result, the riverbed inside the river entrance will be gradually silted along with the tide, when the sediment of siltation comes from the mouth bar and shoals mainly but comes from the land field seldom; the seabed outside the river entrance will be scoured gradually.

The relative strength between the runoff and tide also affects the evolution of erosion and deposition in local areas. The east branch of Shazhu Village is the tributary of Lingjiang River and the west branch is the trunk stream. According to relevant information, the tributary was clear and rapid ever; the largest depth is about $6 \mathrm{~m}$ deep. However, the tributary has almost dried up after the runoff decreasing and the topographic condition affecting in recent years. Large areas of tidal flats have been formed by the accumulational sludge and some areas have been hardening.

\subsection{The Dimension of Estuary Section Under the Combined Influence of Runoff and Tide}

In the given conditions of water, sediment and terrain, different riverbed sections have different stabilities or activities. The riverbed will strive to form the section shape of minimum activity in the changing process of erosion and deposition. The variation trend of riverbed is called the minimum activity hypothesis [8]. The direct index of riverbed activity is the amplitude of variation of erosion and deposition in the lengthways or widthways direction. The amplitude depends on a number of factors (e.g. the relative strength between the runoff and tide, terrian condition). The common section shape of riverbed is the most stable one in the given conditions, because the riverbed will strive to possess the minimum activity in the changing process of erosion and deposition.

Luo [9] has given out the relationship between the crosssectional area and the average ebb flow including the runoff volume. The runoff and tide play an important role in shaping the riverbed section in view of the fact that the Jiaojiang River broadens outward from Niutoujing like a 
shape of horn. In the estuaries of similar conditions for incoming sediment and riverbed sediment constituent, the relation between the cross-sectional area $A$ and the average ebb flow including the runoff volume $Q$ can be written as follow:

$$
A=M Q^{8 / 9}
$$

Luo [9] has ever got $M=3.84$, according to the data of Sheyang River, Yong River and Liu River. This paper has obtained $M=3.68$ by fitting data of the cross-sectional flow in $1 \#, 2 \#$ and $5 \#$ test verticals in Jiaojiang River estuary. The value of $M$ is similar to that got by Luo [9] (see Fig. 16). It shows that the higher tidal flow will maintain the larger dimension of riverbed section. The runoff and tide can make primary effect on maintaining the underwater morphology of estuaries.

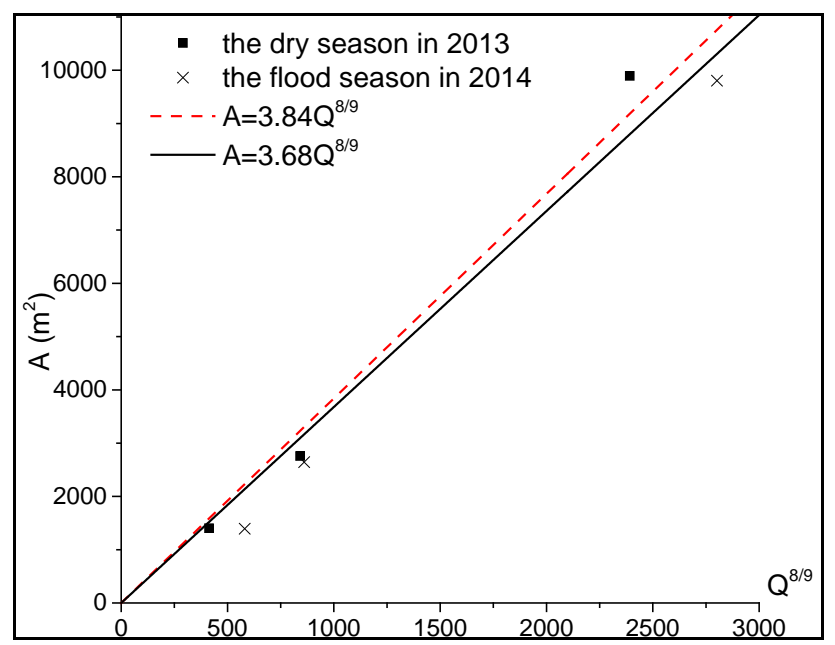

Fig. (16). The relation between the cross-sectional area and the average ebb flow.

\subsection{The Influence Made by Sluice Construction on the Water-Sediment Characteristics and the Riverbed Evolution of Erosion and Deposition}

In the research of sluice construction especially in the macro-tidal estuary, the hydrodynamic changes and siltation in the downstream area of sluice must be sufficiently studied. Based on the latest measured topographic data, Nanjing Hydraulic Research Institute has built the two dimensional tidal current and sediment mathematical model from Jiaojiang River estuary to Taizhou Bay [4]. The current and sediment concentration have been computed and verified by employing the latest hydrologic data. The changes of some aspects (e.g. tidal level, tidal current, tidal volume, the erosion and deposition of riverbed) caused by sluice construction in four areas (i.e. Miaolonggang, Niutoujing, Yantou and Toumen Island) have been analyzed. The computation result of mathematical model indicates as follows :

(1) The water-sediment characteristics in the downstream area of sluice will change for a certain degree after the sluice built in Miaolonggang. The high tidal level will raise; the low tidal level will drop slightly. The flow velocity of both the flood and ebb tide will decrease; the decreasing degree will be lower in the farther downstream area and unconspicuous outside Sanjiangkou. The tidal prism in the sections of Lingjiang River and Jiaojiang River will decrease; the decreasing degree will be higher in the closer area to the sluice. The sediment concentration of both flood and ebb tide will decrease and that of ebb tide will decrease obviously.

(2) Lingjiang River and Jiaojiang River will become the channel reservoir after the sluice built in Jiaojiang River Mouth. The siltation caused by little sediment from the basin will be slight in the upstream of sluice. The riverbed changes of erosion and deposition are mainly affected by the drainage of gate opening; Lingjiang River will be scoued mainly; Jiaojiang River will be scoued in the grooves and silted on the shoals. The high and low tidal levels will change slightly. The flow velocity of both the flood and ebb tide will decrease in the downstream inlet of sluice. A harbor waters will form in the downstream area of sluice and the sediment concentration in the area is similar to that in the open sea. The sluice construction in Jiaojiang River Mouth will make little effect on the sediment concentration of the open sea.

The siltation in the downstream area of sluice is mainly caused by the deformation of tidal wave and the reduction of both the runoff volume and tidal discharge. The three factors are related and restricted mutually [10]. Increasing the discharged flow can improve the situation of siltation in the downstream area of sluice fundamentally. Making use of hydraulic power by employing the appropriate gate control scheme to scour the siltation is the effective and primary measure to prevent the siltation.

\section{CONCLUSIONS}

(1) The high tide level appears to be higher; the tidal range and the time difference between ebb tide and flood tide present a reduction when the runoff intensity is higher in the flood season than in the dry season. The changes of relative strength between the runoff and tidal current can regularly influence the water-sediment characteristics.

(2) The flood will weaken the tidal wave severely. The low tide level rised up significantly and the high tide level manifested no abnormity. As a result, the tidal range decreased significantly when the flood surges.

(3) The turbidity maximum will move downstream along with the runoff intensity strengthening. The vertical sediment concentration gradient is greater in the riverway controlled by runoff than in which controlled by tide.

(4) The sediment of riverbed surface resuspends under the entrainment influence of current. The sediment enters into the riverway with the tidal current or moves downstream with the runoff. It is why the sediment concentration in the bottom is high both in the flood and dry season.

(5) The evolution of erosion and deposition in Jiaojiang River estuary shows the obvious characteristics of seasonal variation. The change of relative strength between the runoff and tide is an important factor of that. In general, Lingjiang River is mainly controlled by runoff or flood; Jiaojiang River is under the effect of both runoff and tidal current; the area outside Jiaojiang River mouth is mainly under the control of tidal current. Lingjiang River and Jiangjiang River inside the estuary entrance 
had taken siltation as the primary in 2005-2013, on account of the reduced runoff in recent years and the back-silting caused by limiting sand excavation. If the influence of human activities is out of consideration, the shoreline shape and riverbed conditions are relatively stable in Jiaojiang River estuary.

(6) The runoff and tide can make primary effect on maintaining the underwater morphology of estuaries. The relation between the cross-sectional area $\mathrm{A}$ and the average ebb flow including the runoff volume $\mathrm{Q}$ can be written as the relation: $A=3.68 Q^{8 / 9} A=3.68 Q^{8 / 9}$

(7) The sluice built in the riverway making the runoff volume declining sharply is the key factor of the changes of water-sediment characteristics and siltation in the downstream; the influences will be larger in the closer area to the sluice. The sluice built in the broadening estuary will block the sediment exchange between Jiaojiang River Mouth and open sea. The sediment concentration in the area is similar to that in the open sea. Increasing the discharged flow can improve the situation of siltation in the downstream area of sluice fundamentally.

\section{CONFLICT OF INTEREST}

The authors confirm that this article content has no conflict of interest.

\section{ACKNOWLEDGEMENTS}

This work was supported by the Special Research Foundation for Public Welfare Industry of Ministry of Water
Resources (201201070) and the Major Science and Technology Project of Ministry of Transport (201132874640).

\section{REFERENCES}

[1] S. Y. Zhang, H. Xu, "The engineering report for gathering and analyzing the fundamental data before sluice construction in Jiaojiang River estuary”, Zhejiang: Zhejiang surveying institute of estuary and coast, 2014.

[2] A. H. Bi and Z. L. Sun, "A preliminary study on estuarine process of the Jiaojiang River”, Journal of Sediment Research, no. 3, pp. 12-26, 1984.

[3] J. R. Ma, Y. Q. Guo and G. L. Zou, "Analysis on changes of flow and sediment characteristics caused by Jiaojiang River control works”, Yangtze River, vol. 44, no. 21, pp. 85-89, 2013.

[4] X. D. Zhao, X. Z. Zhang and W. Y. Xia, "The Research on the Influence of Siltation in the Downstream Area of Sluices Built in Jiaojiang River and Lingjiang River", Nanjing: Nanjing hydraulic research institute, 2015.

[5] B. G. Li, C. H. Wang, H. Q. Zhou, X. Y. Wu and H. Yang, "Adjustment mechanism on the erosion and accretion of riverbed in the Jiaojiang Estuary in Zhejiang Province, China”, Acta Oceanologica Sinica, vol. 31, no. 5, pp. 89-100, 2009.

[6] L. B. Zhao, "Mixing action of saline water with fresh water of Jiaojiang River estuary on the mouth bar”, Marine Sciences, no. 1, pp. 61-64, 1992.

[7] Y. K. Zhu, "Some characteristics of the Jiaojiang mountain river estraryunder strong tides in Zhejiang Province", Geographical research, vol. 5, no. 1, pp. 21-31, 1986.

[8] G. R. Dou, "The riverbed morphology of alluvial plains rivers and tidal estuaries”, Journal of Hydraulic Engineering, no. 2, pp. 1-13, 1964.

[9] Z. S. Luo, "Estuarine Regulation and Sudden Siltation During Heavy Wind," Beijing: China Ocean Press, pp. 315-317, 2009.

[10] Z. S. Luo, and P. Y. Gu, "Sedimentation associated with tidal barriers in china's estuaries and measures for its reduction", Estuarine Comparisons, pp. 611-622, 1982. 